\title{
Biochemical Studies of Chlorfluazuron and Diflubenzuron Effect on Chitinase and Phenol Oxidase and Biological Studies on the Black Cutworm Agrotis ipsilon (HUFN.) (Lepidoptera:Noctuidae). Hanan S. Taha and Mona K. Al-Hadek Central Agricultural Pesticide Laboratory, Dokki-Giza
}

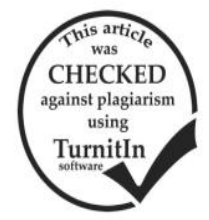

\begin{abstract}
Chlorfluazuron and diflubenzuron effect were biologicaly and biochemicaly were studied by treated Agrotis ipsilon at early stage $2^{\text {nd }}$ instar larvae with two concentrations to show the stages diformities and changes in chitinase and phenoloxidase activities at three time intervals. The chitinase activity showed increase at $48 \mathrm{~h}$ compared with $24 \mathrm{~h}$ and $72 \mathrm{~h}$. Else, significant differences between the three times of treatment were observed in treated and control larvae. For illustration the mean of chitinase activities of chlorfluazuron $\mathrm{LC}_{30}$ treatment were (333.3 $\pm 7.0,319.6 \pm 2.4$ and 282.6 $\pm 3.1 \mathrm{ug} \mathrm{NAGA} / \mathrm{min} / \mathrm{g}$. b.wt. for 24,48 and $72 \mathrm{~h}$ were noted. Phenoloxidase enzymatic activity after $72 \mathrm{hrs}$ revealed significant decline at higher concentration. After 24 hrs of treatment, the highest phenoloxidase activity was with chlorfluazuron (170 \pm 4.58 O.D. units/ min/g.b.wt.) and followed by drastic decline at higher concentrations and exposure period ( $91.6 \pm 0.99$ O.D. units/ min/g.b.wt.). The percentage of phenoloxidase activity compared with the control shows varied from each other according to larvae exposure period. The activity at the three different time intervals show increase at $48 \mathrm{~h}$ in compared with $24 \mathrm{~h}$ and $72 \mathrm{~h}$. The higher percentage comparing with control of phenoloxidase activity and the lowest were 83.58 to $-5.4 \%$ for chlorfluazuron at $42 \mathrm{~h}$, of $\mathrm{LC}_{30}$ and chlorfluazuron at $24 \mathrm{~h}$, of $\mathrm{LC}_{50}$. The biological results showed that the two compounds induced morphological abnormalities of all life stages of A.ipsilon, increase larval and pupal duration and decrease fecundity and fertility.
\end{abstract}

\section{INTRODUCTION}

The black cutworm, Agrotis ipsilon (Hufn.) (Lepidoptera:Noctuidae) is a major pest of cutworms permanently shakes Egyptian crops at three to four generations each year resembling different countries. Cutworm is nocturnal (night time) as it attacks the young seedling of the plants at night. Larvae can damage many cultivated and wild plant species as tobacco, potato, tomato, lettuce, cabbage, spinach, turnip, eggplant, broccoli and many ornamental plants (Watson 2016). The larva feed on the plants by cutting their stem either below or just above the ground level, hide and live inside the cracks and holes in the soil during the day Busching and Turpin (1977). The percent of plant damage varies from $20-37 \%$ at optimum temperatures of $26{ }^{\circ} \mathrm{C}$ and $75 \%$ relative humidity, (Archer et.al. 1980), but in severe cases the damage occur as much as $80 \%$ depending on the severity of infestation (Fernandes et.al. 2013). All organisms generate a wide variety of hydrolytic enzymes that exhibit different substrate specificities useful for various functions. Chitin is a polysaccharide occurs in fungi, some algae and many invertebrates, including insects. Thus, chitin synthesis and degradation could represent specific targets for fungicides and insecticides. Chitinases catalyzes the hydrolysis of chitin, to produce $\mathrm{N}$-acetyl-d-glucosamine and chitobiose or chitotriose, and can be classified as endochitinases or exochitinases, and currently classified into two different families of glycosyl hydrolases, namely family 18 and 19 , on the basis of amino acid sequence similarities (Hirose et.al. 2010). Phenoloxidase is responsible for the biosynthesis of melanin pigment in animals and plants and play important role in insect immunity system that showing both monophenol monooxygenase and diphenoloxidase activity. Melanization followed by tanning and Sclorotization that make insect cuticle is tanned and hardened, ( $\mathrm{Lu}$ and Jiang 2007). Chitinase and phenoloxidase inhibitors have become subject of increasing interest very important to investigate and so are necessary to comprehend its biochemical properties.
Insecticides with growth regulating properties (IGR); recently exist in markets affect insects by regulating or inhibiting specific biochemical pathways or processes essential for insect growth and development principally to death due to abnormal regulation of hormonemediated cell or organ regulation (Gholami et.al. 2013). Chlorfluazuron $\left(\mathrm{C}_{20} \mathrm{H}_{9} \mathrm{Cl}_{3} \mathrm{~F}_{5} \mathrm{~N}_{3} \mathrm{O}_{3}\right)$ and diflubenzuron $\left(\mathrm{C}_{14} \mathrm{H}_{9} \mathrm{ClF}_{2} \mathrm{~N}_{2} \mathrm{O}_{2}\right)$ is stomach toxin act as insect growth regulator belonging to class benzophenylurea, inhibits chitin biosynthesis of insect cuticle, loses cuticle elasticity and firmness, results in abortive molting and give a good control of various pests and selective toxicity especially lepidoptera, even at low dose rate (10-50 g a.i. /ha), possess low environmental persistence, low mammal toxicity and rapid dissolution, (Perveen and Miyata 2000). This study aim to investigate the effect of the two insect growth regulators treatment on the biological fitness of the target pest and detect the changes that conferring biochemically by measuring two biomarkers is chitinase and phenoloxidase enzyme at three time intervals throughout the A. ipsilon $2^{\text {nd }}$ instar larvae exposure period

\section{MATERIALS AND METHODS}

Rearing Insects:

A big culture of $A$. ipsilon was reared in the CAPL for many years on castor-bean leaves (Ricinus communis L.) till the pupal stage under conditions $25 \pm$ $2{ }^{\circ} \mathrm{C}, 65 \pm 5 \%$ R.H. and light: dark period was 12 hours. Neonate Larvae reared in big glass containers with sawdust in the bottom covered with muslin cloth fastened with rubber bands and cleaned daily to avoid any type of infection. The $4^{\text {th }}, 5^{\text {th }}$ and $6^{\text {th }}$ instar were reared individually in plastic vials to avoid cannibalism. Pupae were putted in ventilated cage and adults emerged were fed on piece of cotton soaked with a $10 \%$ sucrose solution and fresh leaves of Nearium oleander (L.) were used for oviposition. Laid eggs were collected and kept in glass container for hatching at the same rearing room. This culture was used for the 
toxicological, biochemical bioassay and the growth parameter measurement. The process of culture rearing was repeated and maintained throughout the experimental studies.

\section{Insecticides tested:}

Insecticide formulations: chlorfluazuron 5\% SC (Efcoron) also known as Atabron and diflubenzuron $48 \%$ SC (Newbenzuron) also known as Dimilin, were obtained from Central Agricultural Pesticide Laboratory under Kam Egyptian Agricultural Chemical Company as formulation supplier and Jiangyin Suli chemical Co.China as supplier of the active ingredients.

\section{1-Treatment procedure :}

The initial bioassay was carried out by dipping castor bean leaves in serial insecticide concentration preparations based on ppm by diluting the commercial formulation in water. The treated leaves were allowed to dry at room temperature, introduced to $2^{\text {nd }}$ instar larvae in 3 replicates petri dish and water only used for control. Ten larvae to each dish were provided. Then mortality percent was recorded after $96 \mathrm{~h}$ after treatment and corrected by Abbott formula (Abbott, 1925). Probit analysis for mortality data were completed using (Finney, 1971) and $\mathrm{LC}_{30}, 5_{50}$ were calculated. Subsequently a quantity of $2^{\text {nd }}$ larvae culture was exposed to castor bean leaves treated with $\mathrm{LC}_{30}$ and other quantity treated with $\mathrm{LC}_{50}$ values that achieved from the previously described bioassay. Every batch was divided into three exposure duration were 24,48 , and $72 \mathrm{~h}$, and after each exposure time the survived larvae were collected and kept freezing for enzyme activities determination.

\section{2-Determination of enzymes activities: Determination of chitinase activity:}

Colloidal chitin (substrate preparation) was prepared according to Bade and Stinson (1981). The reaction mixture was conducted according to Ishaaya and Casida (1974), and N-acetylglucose amine was determined by the sensitive method of Waterhouse et.al. (1961). The enzyme activity was expressed as $\mu \mathrm{g} \mathrm{N}$ acetylglucose amine (NAGA) $\times 103 / \mathrm{min} / \mathrm{gm}$ fresh weight.

\section{Determination of Phenoloxidase activity:}

Phenoloxidase activity was determined according to a modification of Ishaaya (I971), in a reaction mixture consisting of $0.5 \mathrm{ml}$ phosphate buffer $(0.1 \mathrm{M}$, $\mathrm{pH} 7), 200 \mu \mathrm{l}$ enzyme solution and $200 \mu \mathrm{l}$ catechol solution (2\%). Prior to the initiation of the reaction, the substrate and other ingredients of the reaction mixture were separately incubated at the optimum temperature of the reaction $\left(25^{\circ} \mathrm{C}\right)$. Enzyme reaction was initiated by adding catechol solution. Then after exactly $1 \mathrm{~min}$, the optical density was determined. Zero adjustment was against sample blank at $405 \mathrm{~nm}$.

\section{3-The effect on biological stages estimation:}

The biological effects were studied at the two concentrations against $2^{\text {nd }}$ instar larvae of $A$. ipsilon. One hundred larvae were introduced to a big container covered with muslin and filled with a potato leaves treated with $\mathrm{LC}_{30}$ and $\mathrm{LC}_{50}$ concentration that estimated from the initial bioassay and three replicate were prepared. Control was treated with water only. After
$24 \mathrm{~h}$ feeding on treated leaves, untreated leaves were introduced. Each instar developmental periods, body weight, percentage of pupation and adult emergence were recorded, also count of egg to every female survived were recorded and hatchability were calculated.

Statistical analysis:

Data were subjected to the probit regression analysis using the Ehab-Soft program according to Finney 1971 methods and Abbott 1925 was included and the $\mathrm{LC}_{50}$, and $\mathrm{LC}_{90}$ values and their $95 \%$ confidence limits were calculated for the baseline toxicity. The differences between the two compounds, exposure time and the concentration were analysis using the SPSS-19 statistical programme 2016. Means were separated using the least significant different at 5\% level.

\section{RESULTS AND DISCUSSION}

\section{Lethal and Sublethal Effects on $2^{\text {nd }}$ instar larvae of A.ipsilon: \\ 1-Toxicity of chlorfluazuron and diflubenzuron:}

Table 1, show the lethal and sublethal concentrations of both IGR compound tested $\left(\mathrm{LC}_{30}\right.$ and $\mathrm{LC}_{50}$ ) that determined against A.ipsilon. Both goodnessof-fit tests indicated that the regression analysis fitted well to the chlorfluazuron $(\mathrm{p}=0.93)$ and diflubenzuron data points $(p=0.98)$. Significant differences were observed between the IGR slope lines $(p<0.001)$. The $\mathrm{LC}_{30}$ and $\mathrm{LC}_{50}$ values in ppm that achieved were (134.38, 266.9 and 2002, 3744.5 for chlorfluazuron and diflubenzuron respectively. Nearby the toxicity effect result of both compounds that represent the phenylurease chemical group some searches stated that those compounds exerted excellent control for lepidopteran pests, identically, the phenylthiourea insecticide members differ between each other in their potency and toxicity, however (Li, et.al. 2013), discovered the insecticidal mechanism of NK-17 that was could bind to sulfonylurea receptor (SUR) of Blatella germanica to inhibit the chitin synthesis with stronger affinity comparing to diflubenzuron and glibenclamide. Da Silva and Mendes (2007) reported that diflubenzuron residual effects caused great Aedes aegypti (L) larval mortality. The diflubenzuron WP brought about $100 \%$ inhibition of adult housefly emergence (Tilak et.al. 2010), and inhibited $80 \%$ of Culex adult emergence for 7-21 days in abandoned wells (Sadanandane et.al. 2012). Peters and Fitzgerald (2003) proved that the mound-building of subterranean termite Coptotermes acinaciformis (Froggatt) and Colony was declined till 12 week after bait application of chlorfluazuron.

Table 1. Toxicity of chlorfluazuron and diflubenzuron on $2^{\text {nd }}$ instar larvae of $A$.ipsilon.

\begin{tabular}{lcccc}
\hline \multirow{2}{*}{ Insecticide } & \multicolumn{4}{c}{ Calculated Responses } \\
& $\mathbf{L C}_{\mathbf{3 0}}$ (F.L.) ppm LC & $\mathbf{5 0}$ (F.L.) $\mathbf{~ p p m}$ & Slope \pm SE & $\boldsymbol{\chi}^{\mathbf{2}}$ \\
\hline \multirow{2}{*}{ Chlorfluazuron } & 134.38 & 266.91 & 1.72 & \multirow{2}{*}{0.43} \\
\multirow{4}{*}{ Diflubenzuron } & $(81.28-222.15)$ & $(186.1-359.3)$ & \pm 0.289 & \\
& 2002 & 3744.5 & 2.06 & 0.153 \\
& $(1225.7-3269.3)$ & $(2864.8-4882.5)$ & \pm 0.305 & \\
\hline
\end{tabular}

2-Effect on Chitinase and phenoloxidase activity:

In this study result of the A.ipsilon larvae treatment by benzophenylurease insecticides is found to 
be induces differential in chitinase and phenoloxidase activity as compared to untreated. Chitinase activity resulted were mentioned in Table 2. Comparing between all the means, treated larvae had greater chitinase activity of both compounds than untreated controls. A significant differences between chitinase activity of all treatments of both compounds were found $(\mathrm{F}=1.34, \mathrm{df} 1=5, \mathrm{df} 2=39$ and $\mathrm{P}=0.267)$. With increase in exposure time the level of chitinase were increased slightly from $24 \mathrm{~h}$ to $48 \mathrm{~h}$ and began to slightly decrease in $72 \mathrm{~h}$ exposure time. Otherwise, significant differences between 24,48 and $72 \mathrm{~h}$ of treatment were observed in enzyme activity of treated and control larvae $(\mathrm{F}=0.279$, $\mathrm{df}=1$ and $\mathrm{P}=0.60)$. For instance the mean of activities of chlorfluazuron $\mathrm{LC}_{30}$ treatment were ranged between (333.3 \pm 7.0 to $282.6 \pm 3.1$ ug NAGA/ $\mathrm{min} /$ g.b.wt. for 24 , 48 and $72 \mathrm{~h}$ noted. The percentage of activity compared with the control also was found in Table 2 and shows that the results were varied from each other according to larvae exposure period. The activity at the three different time intervals show increase at $48 \mathrm{~h}$ in compared with $24 \mathrm{~h}$ and $72 \mathrm{~h}$. The higher value and the lowest were 23.3 to $-1.77 \%$ for chlorfluazuron at $24 \mathrm{~h}$, of $\mathrm{LC}_{30}$ and diflubenzuron at $72 \mathrm{~h}$, of $\mathrm{LC}_{50}$. Similar results were found to be a better review for the effect of IGRs compound on chitinase activity likewise Abd ElMageed and Shalaby(2011), Found that mixing IGR compounds with some pyrethroids or organophosphates insecticide caused an increase in chitinase activity ranging between $17.14 \%$ and $53.34 \%$ in Spodoptera littoralis (Boisd.) more than the control. Also Sabry and Khedr (2014), observed elevation in phenoloxidase in 4th instar larvae of $S$. littoralis treated with tebufenozide, flufenoxuron and teflubenzuron and reduction in chitinase activity. Also molting hormone agonist methoxyfenozide and tebufenozide decreased phenoloxidase activity. Either Al-Mokhlef et.al. (2012), recorded that, inhibition in chitin and protein synthesis was calculated to be $88.9 \%$ and $61.85 \%$, respectively in $5^{\text {th }}$ instar Schistocerca gregaria nymphs, treated with $\mathrm{LC}_{75}$ of the chitin synthesis inhibitor teflubenzuron, and cuticle chitin and total soluble protein dry weight were 8.5 and $7.85 \mathrm{mg} / \mathrm{nymph}$ less than control, respectively.

Table 2. Chitinase activities at three time intervals of treated $2^{\text {nd }}$ instar larvae of $A$.ipsilon.

\begin{tabular}{lccccccc}
\hline \multirow{2}{*}{ Insecticide } & \multirow{2}{*}{ Conc. } & \multicolumn{7}{c}{ Chitinase (ug NAGA/ min/g.b.wt.) } \\
\cline { 3 - 8 } Chlorfluazuron & $\mathrm{LC}_{30}$ & $333.3 \pm 7.0$ & 23.3 & $319.6 \pm 2.41$ & 20.9 & $282.6 \pm 3.1$ & 0.462 \\
& $\mathrm{LC}_{50}$ & $297 \pm 1.27$ & 9.87 & $305.3 \pm 2.16$ & 15.5 & $264.6 \pm 2.16$ & -5.93 \\
\multirow{3}{*}{ Diflubenzuron } & $\mathrm{LC}_{30}$ & $272 \pm 1.27$ & 0.628 & $318 \pm 2.99$ & 20.3 & $357 \pm 2.92$ & 26.9 \\
Control & $\mathrm{LC}_{50}$ & $284.6 \pm 1.21$ & 5.29 & $337 \pm 3.36$ & 27.5 & $276.3 \pm 2.46$ & -1.77 \\
\hline a & ----- & $270.3 \pm 5.0$ & ----- & $264.3 \pm 2.27$ & ----- & $281.3 \pm 1.7$ & ---- \\
\hline
\end{tabular}

a:\% of control $=($ Test - Control $) /$ Control $\times 100 ;$ Letters mean the significant differences between treatments

The result of phenoloxidase activities were cited in Table (3). The percentage of activity compared with the control also was found in Table (3) and shows that the results were varied from each other according to larvae exposure period. The results shows that after 24 hrs of chlorfluazuron treatment of A.ipsilon $2^{\text {nd }}$ instar larvae, only the $\mathrm{LC}_{50}$ concentrations resulted in significant increase in phenoloxidase activity as compared to control. The analysis of phenoloxidase enzymatic activity after $72 \mathrm{hrs}$ revealed significant decline at higher concentration. After $24 \mathrm{hrs}$ of treatment, the highest phenoloxidase activity was to chlorfluazuron (170 \pm 4.58 O.D. units/ $\mathrm{min} /$ g.b.wt.) and followed by severe decline at higher concentrations and exposure period (91.6 \pm 0.99 O.D. units/ $\mathrm{min} / \mathrm{g}$.b.wt.). The percentage of the control was found in table 3 . The activity at the three different time intervals show increase at $48 \mathrm{~h}$ in compared to $24 \mathrm{~h}$ and $72 \mathrm{~h}$. The higher value and the lowest were 83.58 to $-5.4 \%$ for $\mathrm{LC}_{30}$ and $\mathrm{LC}_{50}$ of chlorflua zuron at42 h.

This data reveal a significant differences between phenoloxidase activity of all treatments of both compounds were found $(\mathrm{F}=4.5, \mathrm{df} 1=5, \mathrm{df} 2=39$ and $\mathrm{P}=0.002)$ and significant differences between time of exposure $24 \mathrm{~h}$ to $48 \mathrm{~h}, 72 \mathrm{~h}$ and control $(\mathrm{F}=0.08, \mathrm{df}=1$ and $\mathrm{P}=0.779)$. These results were similar to that of Rahimi, et.al. 2013, who they found no statistical differences in phenoloxidase activity of Ephestia kuehniella larvae treated by pyriproxyfen, but hexaflumuron after 1-3 hours of post-injection. The phenylthiourea is the well-known and widely used inhibitor of phenoloxidase, the inhibitor function is the control of the activity in insects and prevent melanization and sclerotization reaction that might be regulating the activity during infection, wounding and metamorphosis (Sugumaran and Nellaiappan 2000\& Ryazanova et.al. 2012). Phenol oxidase activity always affected by some stressor as pesticides and others like the proceeding reviews, Bai et.al. (2014), said that the phenoloxidase activity were affected by kojic acid treatment in larval of oriental fruit fly, Bactrocera dorsalis, and developmental periods were prolonged. While in rosaceous branch borer, Ospheranteria coerulescens phenoloxidase activities were lost $50 \%$ after a60 min incubation when treated with kojic acid (Gholami et.al. 2013). Assar, et.al. (2012), found decrease in phenoloxidase in $4^{\text {th }}$ larval instar of culex treated with cyromazine. Ibrahim et.al. 2015, mentioned that phenoloxidase activity decreased in the Heterorhabditis zealandica infected A. ipsilon larvae compared with the control. Mirhaghparast, et.al. (2013), reported highest activity of phenoloxidase obtained at 6-12 hours post-injection of $5^{\text {th }}$ larval instars of $S$. littoralis by spor of Beauveria bassiana and Metarizium anisopliae. And a significant increase in phenoloxidase level were found in 3 and $4^{\text {th }}$ instar larvae $S$. litura treated by $B$. bassiana at $4.0 \times 106$ spores $/ \mathrm{ml}$ after $24 \mathrm{hrs}$ of infection (Bali and Kaur 2013). The fluctuation in decrease and increase in phenoloxidase activity may affected by some factors as stated by, Cornet et.al. (2013), found Culex phenoloxidase activity was higher in larvae than adults, in females than males, and in resistance males than their susceptible, but activity declines with adult age. 
Table 3. Phenol oxidase activities at three time intervals of treated $2^{\text {nd }}$ instar A.ipsilon.

\begin{tabular}{|c|c|c|c|c|c|c|c|}
\hline \multirow{2}{*}{ Insecticide } & \multirow{2}{*}{ Conc. } & \multicolumn{6}{|c|}{ Phenol oxidase (O.D. units/ min/g.b.wt.) } \\
\hline & & $24 h \pm S E$ & $\%$ control & $48 \mathrm{~h} \pm \mathrm{SE}$ & $\%$ control & $72 \mathrm{~h} \pm \mathrm{SE}$ & $\%$ control \\
\hline \multirow{2}{*}{ Chlorfluazuron } & $\mathrm{LC}_{30}$ & $170 \pm 4.58$ & 83.58 & $119.6 \pm 3.63$ & 33.48 & $91.6 \pm 0.99$ & 11.3 \\
\hline & $\mathrm{LC}_{50}$ & $87.6 \pm 1.46$ & -5.4 & $96.6 \pm 1.46$ & 7.8 & $90.0 \pm 1.27$ & 9.3 \\
\hline \multirow{2}{*}{ Diflubenzuron } & $\mathrm{LC}_{30}$ & $96.6 \pm 0.73$ & 4.32 & $112.6 \pm 2.37$ & 25.6 & $128.0 \pm 2.1$ & 55.5 \\
\hline & $\mathrm{LC}_{50}$ & $95.3 \pm 1.21$ & 2.91 & $143.0 \pm 1.68$ & 59.6 & $102.3 \pm 1.68$ & 24.3 \\
\hline Control $\pm \mathrm{SE}$ & ------ & $92.6 \pm 1.46$ & ------ & $89.6 \pm 0.99$ & ------ & $82.3 \pm 1.54$ & ------ \\
\hline
\end{tabular}

$\%$ of control $=($ Test - Control $) /$ Control $\times 100 ;$ Letters mean the significant differences between treatments

\section{3-The effects on biological stages:}

The effect of the growth regulation effect on biological stages of A.ipsilon treated by chlorfluazuron and diflubenzuron at the $2^{\text {nd }}$ instar by $\mathrm{LC}_{30}$ and $\mathrm{LC}_{50}(134.38$, 266.91 and 2002, $3744.5 \mathrm{ppm}$ respectively and the control were in Table 4. Most larvae died during the molting process and a few individuals developed to the $6^{\text {th }}$ instar and then died, while most larvae continue to live. The obtained results also clearly were revealed that the major effect were prolongation of the developmental times in all stages, decrease in body weight for larvae and pupae, deformation of all stages and survived longer before death as compared with the control. Table 4 also shows the effect on fecundity and fertility of each survived female at both concentrations of the two compounds. There was a significant differences between both insecticide in fertility that mean the number of eggs that hatched to every survived adult $(\mathrm{F}=12.78, \mathrm{df}=15, \mathrm{P}=0.075)$ and in adult longevity $(\mathrm{F}=1.88, \mathrm{df}=6, \mathrm{P}=0.171)$ and adult survival $(\mathrm{F}=0.55, \mathrm{df}=16, \mathrm{P}=0.824)$. However there is no significant different were found towards fecundity or the number of eggs that deposited from every survived female. There is a significant differences between both insecticide about larval mortality or larval weight $(\mathrm{F}=0.55, \mathrm{df}=3, \mathrm{P}=0.728)$ and $(\mathrm{F}=0.861, \mathrm{df}=6, \mathrm{P}=0.525)$ respectively. The results clearly show decrease in number of posited eggs and decrease in hatchability of both compounds that spot on the effect of emberyocidal effect against larvicidal effect of both compounds. The Benzoylphenylureas have several effects on larvae lead to diformation of the cuticle in addition to larvicidal and emberyocidal effect. Perveen and Miyata 2000 stated that sublethal exposure of chlorfluazuron topically applied on $5^{\text {th }}$ instars of $S$. litura (F.) affect the fecundity and fertility through significant reduction of ovarian weight and number of mature eggs in pupae and adults. The protein content of ovaries was reduced but the carbohydrate and lipid contents were not affected. Apparently IGRs compound employed malformation effect beside larvicidal and emberyocidal effect in comparison with conventional insecticides. Rumpf et.al. (1998) found that the Micromus tasmaniae Walker treated by diflubenzuron, female Longevity was reduced, total, daily number of eggs was reduced and preoviposition period were extended, that in contrast with azinphos-methyl. The effect of the tested compounds on biological deformities here were similar to other IGR insecticide in A.ipsilon like Khatter (2014) who found that, Flufenoxuron induced morphological abnormalities of all life stages of A.ipsilon, and form incomplete adult wings, increase larval and pupal duration and decrease fecundity and fertility.

Table 4. Development of $\boldsymbol{A}$. ipsilon larvae, pupae and adult under two treatment doses of chlorfluazuron and diflubenzuron.

\begin{tabular}{|c|c|c|c|c|c|}
\hline \multirow{2}{*}{ Estimated parameters } & \multicolumn{2}{|c|}{ Chlorfluazuron } & \multicolumn{2}{|c|}{ Diflubenzuron } & \multirow{2}{*}{ Control } \\
\hline & $\mathrm{LC}_{30} \pm \mathrm{SE}$ & $\mathrm{LC}_{50} \pm \mathrm{SE}$ & $\mathrm{LC}_{30} \pm \mathrm{SE}$ & $\mathrm{LC}_{\mathbf{5 0}} \pm \mathrm{SE}$ & \\
\hline Larval Mortality \% & $30 \pm 0.48$ & $50 \pm 0.48$ & $30.33 \pm 1.11$ & $50.33 \pm 0.27$ & $4.66 \pm 1.8$ \\
\hline Larvae Weight (gm) & $1.05 \pm 0.024$ & $0.93 \pm 0.07$ & $1.24 \pm 0.02$ & $0.96 \pm 0.01$ & $1.32 \pm 0.05$ \\
\hline Larvae diformation $\%$ & $28.66 \pm 1.94$ & $40 \pm 2.1$ & $35 \pm 2.9$ & $49.3 \pm 1.8$ & $2 \pm 0.48$ \\
\hline Pupation \% & $58.66 \pm 4.86$ & $45.3 \pm 1.9$ & $59 \pm 1.92$ & $36.3 \pm 0.73$ & $95.66 \pm 2.3$ \\
\hline Pupae Weight (gm) & $0.49 \pm 0.0048$ & $0.41 \pm 0.0096$ & $0.5 \pm 0.005$ & $0.39 \pm 0.0028$ & $0.44 \pm 0.015$ \\
\hline Pupae diformation $\%$ & $19.33 \pm 4.2$ & $27.67 \pm 0.73$ & $26.7 \pm 1.99$ & $47 \pm 2.54$ & $2 \pm 0.48$ \\
\hline Adult emergence $\%$ & $62.7 \pm 2.42$ & $47 \pm 2.67$ & $51 \pm 3.6$ & $33 \pm 1.27$ & $94 \pm 1.27$ \\
\hline Adult diformation $\%$ & $41.3 \pm 3.9$ & $45.67 \pm 5.46$ & $44.3 \pm 2.46$ & $51.6 \pm 0.73$ & $1.33 \pm 0.27$ \\
\hline Longivity (days) & $7 \pm 0.48$ & $6.66 \pm 0.73$ & $8.66 \pm 0.73$ & $7.66 \pm 0.55$ & $10.33 \pm 0.27$ \\
\hline Adult survival \% & $52 \pm 2.2$ & $39.67 \pm 1.94$ & $58.3 \pm 0.99$ & $44 \pm 2.2$ & $89.33 \pm 1.21$ \\
\hline Fecundity & $146.7 \pm 19.4$ & $88 \pm 9.16$ & $153.3 \pm 18.66$ & $76.66 \pm 5.13$ & $348.66 \pm 8.2$ \\
\hline Fertility & $54.3 \pm 1.99$ & $39 \pm 4.1$ & $60 \pm 3.36$ & $36 \pm 1.92$ & $91.66 \pm 4.46$ \\
\hline
\end{tabular}

Means followed by the same letter at the same column are not significantly different at $\mathbf{p}=\mathbf{0 . 0 5}$.

For explain how insect affected: firstly: the insect dies within the old cuticle and the new cuticle formed within partial moult inhibition, along the ecdysidalline to where the old cuticle remains attached at one point or other. The effect of larval treatment can be displayed at the pupal moult (diformities). Secondly the failure to feed because of displaced mandibles.

The penzoylphenylurease group structures show that the pyridyloxy group is responsible for the transport process of the compound. Substitution of the hydrophobic group on the pyridine ring that lead to increase the hydrophobicity (the intrinsic factor) of the substituents on the aniline and benzoyl ring is that the controlling factor of the insecticidal activity and embryocidal activity Verloop and Ferrell (1977). Additionally the oxidative or degradative metabolism (stability) of the insecticide in the insect body is also reflecting the insecticidal activity Casida and Hajjar, (1979). Those are two points, compensate for each other Chitin synthesis in insects begins by the formation of oligosaccharides synthesized in the epidermal cell, transport to the cuticle and polymeriz to 
form discrete chitin microfibrils and are covalently bound to proteins. Structural integrity is essential for the polymerization of the oligosaccharides, the second polymerization step is the inhibition site by benzoylphenyl ureas. the inhibitory effects is through inhibits the enzyme that catalysing the polymerisation of UDP-N-acetyl glucosamine to chitin or inhibits the transport of UDP-N-acetylglucosamine across biomembranes, inhibits a protease that activates the chitin synthase zymogen and inhibits ecdysone metabolizing enzymes resulting in accumulation of ecdysone. This stimulates chitinase production which results in moult disruption. Additionally the active metabolite of the benzoylphenyl urea is responsible for blocks conversion of glucose to fructose-6-phosphate resulting in inhibition of chitin synthesis (Retnakaran, and Grant (1985).

\section{REFERENCES}

Abbott, W.S. (1925). A method of computing the effectiveness of an inseticide. J. Econ. Entomol., 18:265-267.

Al-Mokhlef, A.A.; Mariy, F.M.; Emam, A.K. and Ali, G.M. (2012). Effect of teflubenzuron on ultrastructure and components of the integument in Schistocerca gregaria (Forskal) 5th instar nymphs. Annals of Agricultural Science, 57(1): $1-6$.

Abd El-Mageed, A.E.M. and Shalaby, SH.E.M. (2011). Toxicity and Biochemical Impacts of Some New Insecticide Mixtures on Cotton Leafworm Spodoptera littoralis (Boisd.). Plant Protect. Sci., Vol. 47, No. 4: 166-175.

Archer, T.L.; Musick, G.L. and Murray, R.L. (1980). Influence of temperature and moisture on black cutworm (lepidoptera: noctuidae) development and reproduction. Can Entomol.Vol.112 (7): 665 673.

Assar, A.A., Abo-El-Mahasen, M.M., Harba, N.M and Rady, A. A. (2012). Biochemical Effects of Cyromazine on Culex Pipiens Larvae (Diptera: Culicidae). Journal of American Science 8(5):443-450.

Bade, M.L. and Stinson, A. (1981). Biochemistry of insect differentiation. A system for studying the mechanism of chitinase activity in vitro. Archs Biochem. Biophyscs., 206 : 213-221.

Bai, P.P.; Chen, E.-H.; Shen, G.-M.; Wei, D.; Wei, D.D. and Wang, J.-J. (2014). Inhibition of phenoloxidase activity delays development in Bactrocera dorsalis (Diptera: Tephritidae). Florida Entomologist, 97(2):477-485.

Bali, G.K. and Kaur, S. (2013). Phenoloxidase activity in haemolymph of Spodoptera litura (Fabricius) mediating immune responses challenge with entomopatho-genic fungus, Beauveria bassiana (Balsamo) Vuillmin. Journal of Entomology and Zoology Studies, 1(6): 118-123.

Busching, M.K. and Turpin, F.T. (1977). Survival and development of black cutworm (Agrotis ipsilon) larvae on various species of crop plants and weeds. Environmental Entomology 6: 63-65.
Casida, J. E. and Hajjar, N. P. (1979). Structure-activity relationships of benzoylphenyl urea as toxicants and chitin synthesis inhibitors in Oncopeltus fasciatus. Pestic. Biochem. Physiol., 11: 33.

Cornet, S.; Gandon, S. and Rivero, A. (2013). Patterns of phenoloxidase activity in insecticide resistant and susceptible mosquitoes differ between laboratory-selected and wild-caught individuals. Parasites and Vectors 6:315.

Da Silva, J.J. and Mendes, J. (2007). Susceptibility of Aedes aegypti (L) to the insect growth regulators diflubenzuron and methoprene in Uberlândia, State of Minas Gerais. Revista da Sociedade Brasileira de Medicina Tropical 40(6): 612-616.

Finney, D.J. (1971). Probit Analysis. Cambridge University Press, London.

Fernandes, F.L.; Diniz, J.F.S.; Silva, P.R. and Mosca, E. (2013). Damage of Agrotis ipsilon (Lepidoptera: Noctuidae) on Coffea Arabica in Brazil. Revista Colombiana de Entomología 39 (1): 49-50.

Gholami, T.; Ghadamyari, M.; Oliaee, A.O. and Ajamhasani, M. (2013). Effects of inhibitors on haemolymph phenoloxidase from rosaceous branch borer, Ospheranteria coerulescens (Coleoptera: cerambycidae). Journal of Plant Protection Research, Vol. 53, No. 4:324-332.

Hirose, T.; Sunazuka, T. and Ōmura, S. (2010). Recent development of two chitinase inhibitors, Argifin and Argadin, produced by soil microorganisms. Proc. Jpn. Acad. Ser. B Phys. Biol. Sci. 86(2): 85-102.

Ibrahim, S.A.M.; Taha, M.A.; Salem, H.H.A. and Farghaly, D.S. (2015). Changes in enzyme activities in Agrotis ipsilon (Lepidoptera, Noctuidae) as a response to entomopathogenic nematode infection. International Journal of Advanced Research Vol. 3 (5): 111-118.

Ishaaya, I. (I971). Observations on the phenoloxidase system in the armored scales Aonidiella aurantii and Chrysomphalus aonidum. Comp. Biochem. physiol., V (39B): 935-943.

Ishaaya, I. and Casida, J.E. (1974). Dietary TH- 6040 alters composition and enzyme activity of housefly larval cuticle. Pestic. Biochem. Physiol., 4:484-490.

Khatter, N.A. (2014). Effect of two insect growth regulators on the development of Agrotis ipsilon Hufn. (Lepidoptera: Noctuidae). Journal of Harmonized Research in Applied Sciences. 2(1):20-28.

Li, Y.; Qin,Y.; Yang, N.; Sun,Y.; Yang, X.; Sun, R.; Wang, Q. and Ling, Y. (2013). Studies on Insecticidal Activities and Action Mechanism of Novel Benzoylphenylurea Candidate NK- 17. PLoS ONE 8(6): e66251.

Lu, Z. and Jiang, H. (2007). Regulation of phenoloxidase activity by high- and low-molecular-weight inhibitors from the larval hemolymph of Manduca sexta. Insect Biochem. Mol. Biol., 37(5): 478-485.

Mirhaghparast, S.K.; Zibaee, A. and Hajizadeh, J. (2013). Effects of Beauveria bassiana and Metarhizium anisopliae on cellular immunity and intermediary metabolism of Spodoptera littoralis Boisduval (Lepidoptera: Noctuidae). ISJ 10: 110-119. 
Perveen, F. and Miyata, T. (2000). Effects of Sublethal Dose of Chlorfluazuron on Ovarian Development and Oogenesis in the Common Cutworm Spodoptera litura (Lepidoptera: Noctuidae). Annals of the Entomological Society of America, Vol. 93(5): 11311137.

Peters, B.C. and Fitzgerald, C.J. (2003). Field Evaluation of the Bait Toxicant Chlorfluazuron in Eliminating Coptotermes acinaciformis (Froggatt) (Isoptera: Rhinotermitidae). J.Econ. Entomol. 96(6): 18281831.

Rahimi,V.; Zibaee, A.; Mojahed, S.; Maddahi,K.; and Zare, D. (2013). Effects of pyriproxyfen and hexaflumuron on cellular immunity of Ephestia kuehniella Zeller (Lepidoptera: Pyralidae). Rom. J. Biol. - Zool., Vol. 58 (2): P. 151-162.

Retnakaran, A. and Grant, G. G. (1985). Control of the oakleaf shredder, Croesia semi purpurana (Kearfott) (Lepidoptera: Tortricidae), by aerial application of diflubenzuron. Can. Ent. 117: 363-369.

Rumpf, S.; Frampton, C. and Dietrich, D.R. (1998). Effects of Conventional Insecticides and OInsect Growth Regulators on Fecundity and Other Life-Table Parameters of Micromus tasmaniae (Neuroptera: Hemerobiidae). Journal of Economic Entomology 91, (1): 34-40.

Ryazanova, A.D.; Alekseev, A.A. and Slepneva, I.A. (2012). The phenylthiourea is a competitive inhibitor of the enzymatic oxidation of DOPA by phenoloxidase. Journal of Enzyme Inhibition and Medicinal Chemistry, 27(1): 78-83.
Sabry, H. M. and Khedr, M. A. (2014). Biochemical and Histological Variations Induced by IGRs in Spodoptera littoralis (Boisd.). Glob. J.Environ. Sci. Toxicol., Vol. 1(2):163-178.

Sadanandane, C.; Doss, P.S.B. and Jambulingam, P. (2012). Efficacy of three formulations of diflubenzuron, an insect growth regulator, against Culex quinquefasciatus Say, the vector of Bancroftian filariasis in India. Indian J. Med. Res. 136: 783-791.

SPSS (2010). Statistical program (SPSS 19.0 Copyright). SPSS Inc.

Sugumaran, M. and Nellaiappan, K. (2000). Characterization of a New Phenoloxidase Inhibitor from the Cuticle of Manduca sexta. Biochemical and Biophysical Research Communications Vol. 268 (2): 379-383.

Tilak, R.; Verma, A.K. and Wankhade, U.B. (2010). Effectiveness of Diflubenzuron in the control of houseflies. J. Vector Borne Dis 47: 97-102.

Verloop, A., and Ferrell, C. D. (1977). In: Pesticide Chemistry in the 20th Century, Vol. 37, pp. 237-270, ACS Symposium Series, American Chemical Society. Washington, D.C.

Waterhouse, D.F.; Hockman, R.H. and Mckellar, J.W. (1961). An investigation of chitinase activity in cockroach and termite extracts. J. Insect Physiol., 6:96-112.

Watson, R.N. (2016). Control of greasy cutworm (Lepidoptera: Noctuidae) in seedling maize. New Zealand Journal of Experimental Agriculture 9(3-4): 351-356.

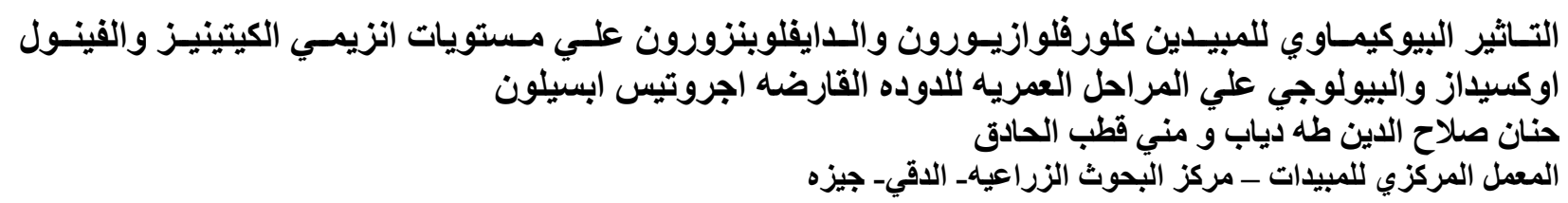

تم اختبار تاثير المبيدين كلورفلوازيورون والدايفلوبنزورون بيوكيماويـا علي انزيم الكيتينـاز والفينول اوكسيداز علي مدي ثنداث

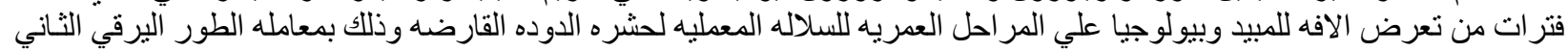

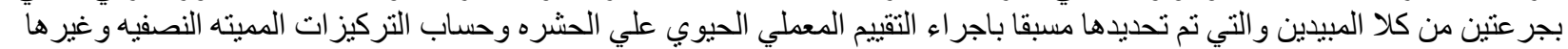

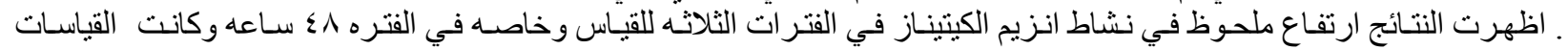

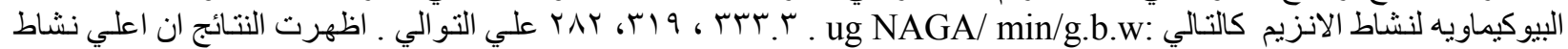

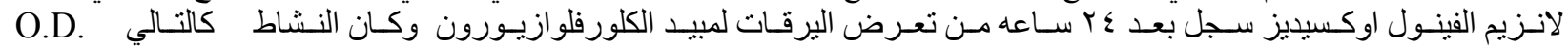

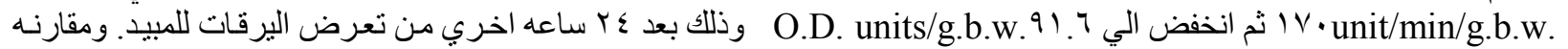

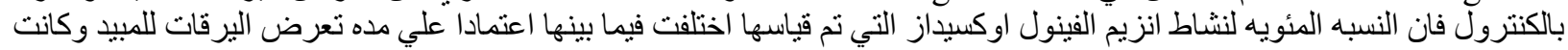

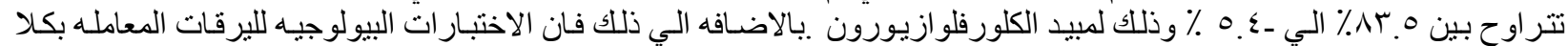

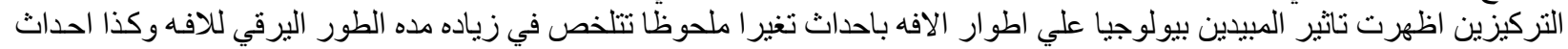

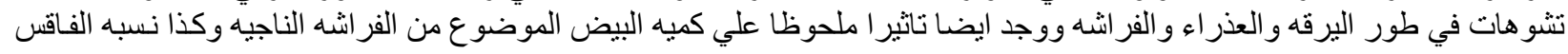

